УДК 666.965.2:693.22

\title{
С.В. ЗУБАНОВ
}

старший преподаватель кафедры городского строительства и хозяйства Самарский государственный архитектурно-строительный университет

\section{E.B. ТКАЧЁB}

магистрант 1-го года обучения факультета транспортного и городского строительства Самарский государственный архитектурно-строительный университет

\section{ОПРЕДЕДЕНИЕ ПРОЧНОСТИ СИЯИКАТНОГО КИРПИЧА И КДАДКИ НЕРАЗРУШАЮЩИМИ МЕТОДАМИ КОНТРОЯЯ}

\author{
DETERMINATION OF THE STRENGTH OF A SILICATE BRICK AND MASONRY, BY METHODS \\ OF NON-DESTRUCTIVE CONTROL
}

Представлень результаты определения прочности силикатного кирпича и кладки с учетом различных факторов приборами неразрушающего контроля. Приведень результаты экспериментальных исследований силикатного кирпича и кладки ультразвуковыли приборами поверхностного и сквозного прозвучивания.

Ключевье слова: силикатный кирпич, скорость прохождения, кирпичная кладка.

Вода, проникающая в капилдяры, оказывает разрушающее действие на строительные конструкции. Основные пути проникновения влаги в строительные конструкции - это выпадение атмосферных осадков, движение грунтовых и талых вод, конденсация водяных паров, диффундирующих через тодщу конструкций.

Стены в процессе эксплуатации подвергаются воздействию влаги двояким образом. С одной стороны, представдяют собой опасность атмосферные осадки. Дождь и снег в ветреную погоду, как известно, обильно смачивают фасад, и защита последнего посредством системы водостоков, выноса кровди над ним и таких архитектурных элементов, как карнизы и эркеры, оказывается малоэффективной.

Но есть и еще один источник увлажнения диффузия водяного пара сквозь ограждающие конструкции из помещения наружу из-за разности парциальных давлений внутри здания и на улице.

Установлено, что снижение прочности строительных материалов под воздействием влаги обусловлено адсорбированным облегчением деформаций. Одновременно, расклинивающее действие водных пленок приводит к снижению однородности структуры. При циклическом замораживании и оттаивании резко падает прочность пористых
There are represented results of determining the strength of a silicate brick and masonry with consideration of various factors by devices of non-destructive control. There are given results of experimental investigations of a silicate brick and masonry by ultrasonic testing devices of surface and through-wall control.

Key words: silicate brick, velocity of passage, masonry.

строительных материалов. Кроме того, вода при миграции в капиллярах переносит растворы солей, которые при кристалдизации приводят к снижению прочности.

Сихикатный кирпич - это группа материалов так называемого автоклавного синтеза. Он готовится методом полусухого прессования из смеси кварцевого песка, воздушной извести и воды. Отформованный кирпич подвергается автоклавной обработке - воздействию насыщенного водяного пара при температурах $170-200{ }^{\circ} \mathrm{C}$ и давлении пара 8-12 атм. В результате синтеза гидросиликатов образуется искусственный камень.

Силикатный кирпич характеризуется высокой механической прочностью, а также высокой теплопроводностью, обладает следующими гигиеническими параметрами:

- воздухопроницаемость стены толщиной 250 мм в тысячу раз выше, чем у бетонной стены толщиной 100 мм, и сопоставима с воздухопроницаемостью одного слоя обычных обоев;

- паропроницаемость в 4 раза лучше, чем у бетона, и в 2 раза по сравнению с деревом.

Главным недостатком сидикатного кирпича является высокий уровень водопоглощения, вследствие которого снижаются теплоизоляционные 
характерис-тики и морозостойкость. Из-за чувствительности к влаге силикатный кирпич категорически противопоказан для строительства фундаментов и цоколей, стен, соприкасающихся с влажными помещениями (безустройства сплошной гидроизоляции). Как следствие, теплоизоляционные характеристики материала (и так оставляющие желать лучшего) на практике становятся непредсказуемыми.

Водопоглощение - это один из важных показатедей качества силикатного кирпича и явдяется функцией его пористости, которая зависит от зернового состава смеси, ее формовочной влажности, удельного давления при уплотнении. По ГОСТ 379-95 [1] водопоглощение силикатного кирпича должно быть не менее $6 \%$.

Для определения влагопоглощения кирпича был проведен эксперимент. В качестве образцов исподьзовади три кирпича из одной партии.

Эксперимент проводился при комнатной температуре. На рис. 1 показан график зависимости изменения влажности от времени нахождения в воде.

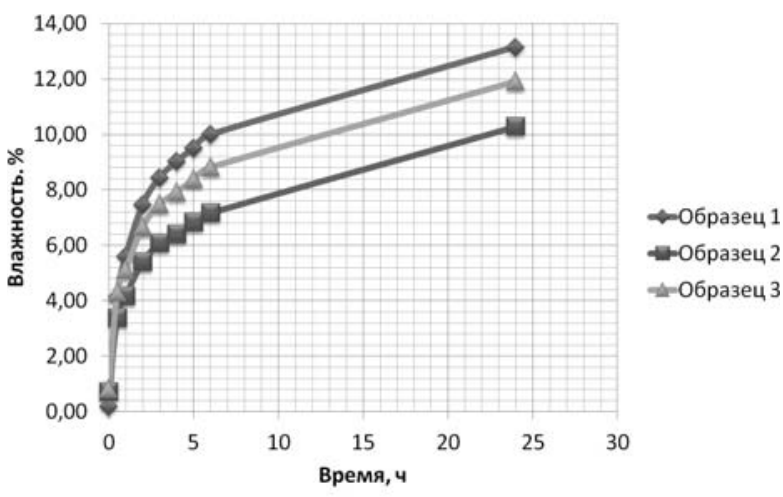

Рис. 1. Графики зависимости изменения влажности от времени нахождения образцов в воде

Во время проведения эксперимента образцы находились в воде с пятидесятипроцентным погружением в воду. Влажность замерялась каждый час в течение первых двенадцати часов. Последний замер был выполнен после замачивания в течение суток.

В ходе анализа необходимо было установить, как изменится скорость прохождения ультразвука в зависимости от влажности и направления прозвучивания. Замеры производились при помощи прибора УК-14 ПМ, который изображен на рис. 3.

Для каждого из образцов были построены графики зависимости скорости прохождения ультразвука по разным направлениям в зависимости от влажности.

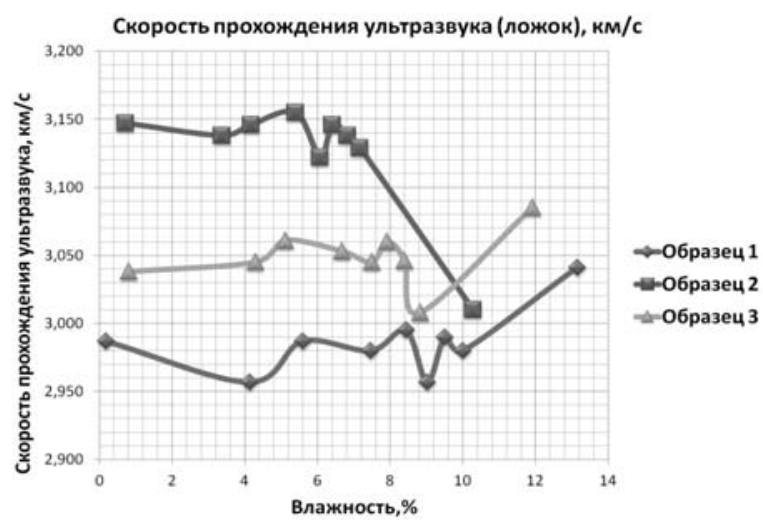

Скорость прохождения ультразвука (постель),
км/с

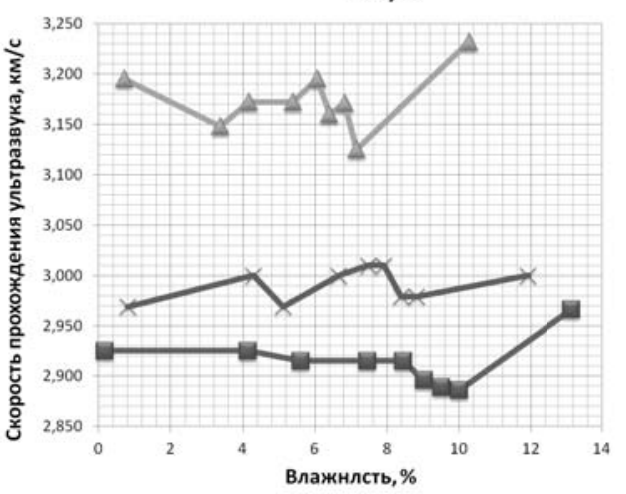

를-06разец 1

-образец 2

-06разец 3

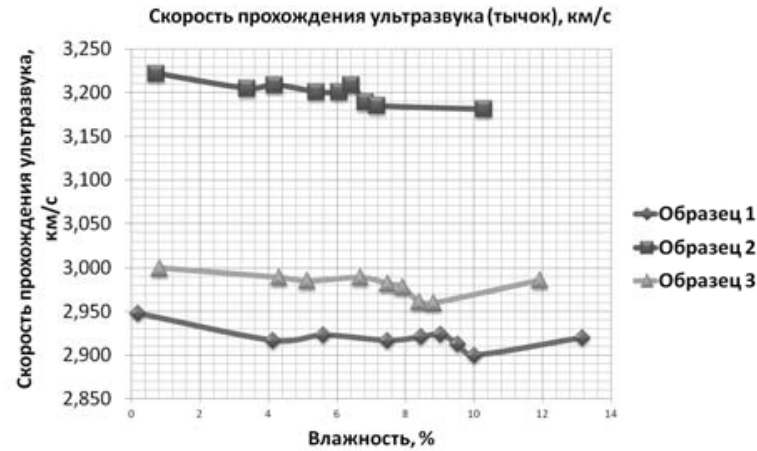

Рис. 2. Графики зависимости скорости прохождения ультразвука через образцы увлажненных кирпичей

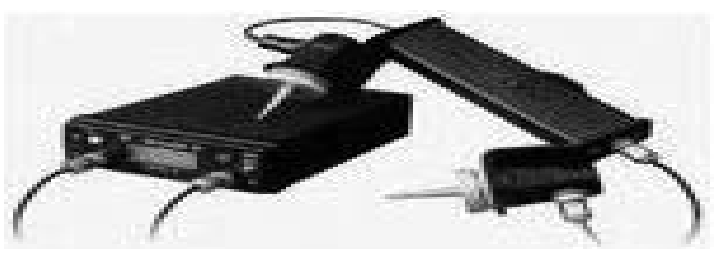

Рис. 3. Прибор УК-14 ПМ

Дия рис. 2 были построены динейные зависимости прохождения ультразвука от влажности силикатных кирпичей по раздичным направдениям (тычок, иожок, постель). 
Графики зависимостей представлены на рис. 4-6.

В результате была получена следующая закономерность, показанная на рис. 7.
Проведение обследования в зимнее время часто осложнено целым рядом факторов, наиболее значительным из которых явдяется определение

Скорость прохождения ультразвука (ложок), км/с

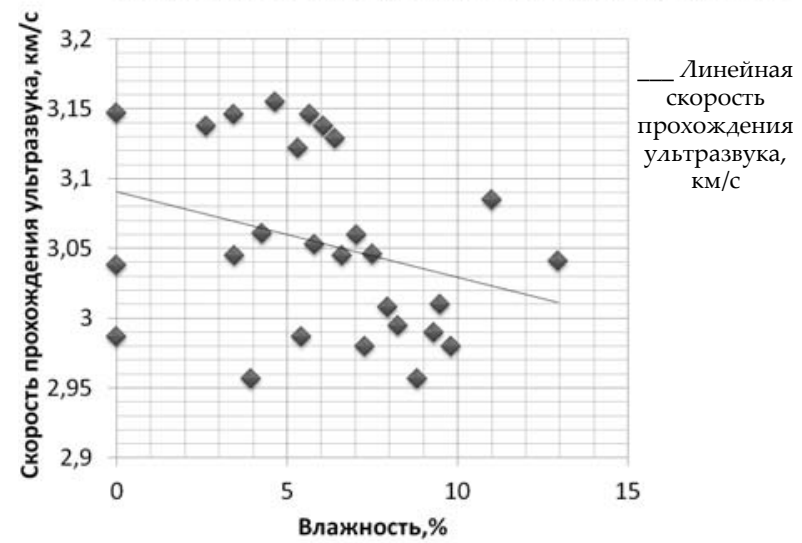

Рис. 4. График зависимости скорости прохождения ультразвука от влажности по ложку кирпича

Скорость прохождения ультразвука (тычок), км/с

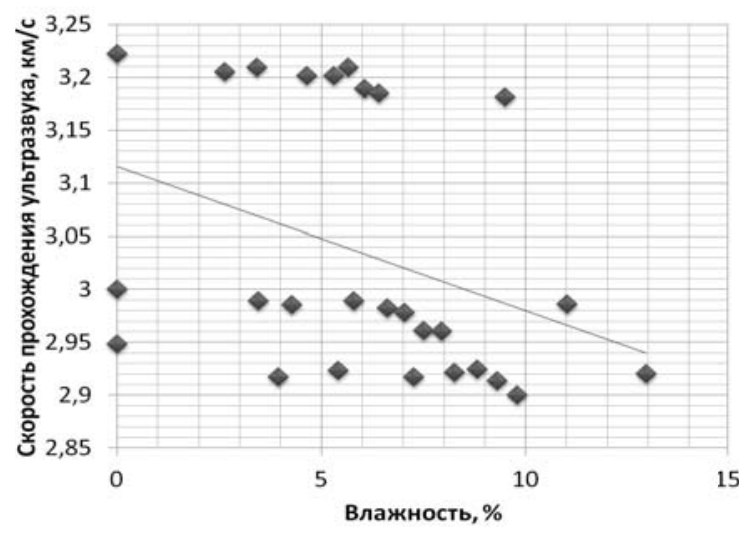

— Аинейная прохождения ультразвука, KM/c

Рис. 5. График зависимости скорости прохождения ультразвука от влажности по тычку кирпича

Скорость прохождения ультразвука (постель), км/с

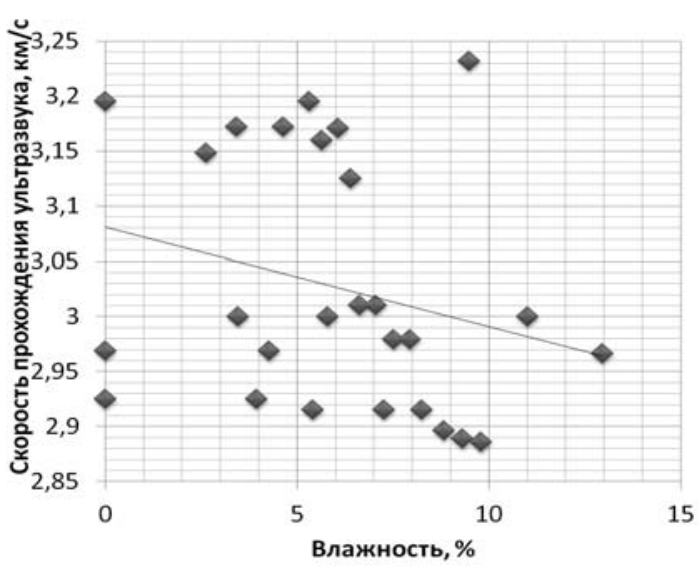

— Линейная

прохождения

ультразвука,

$\mathrm{KM} / \mathrm{C}$

Рис. 6. График зависимости скорости прохождения удьтразвука от влажности по постели кирпича 


\section{Скорость прохождения ультразвука, км/с}

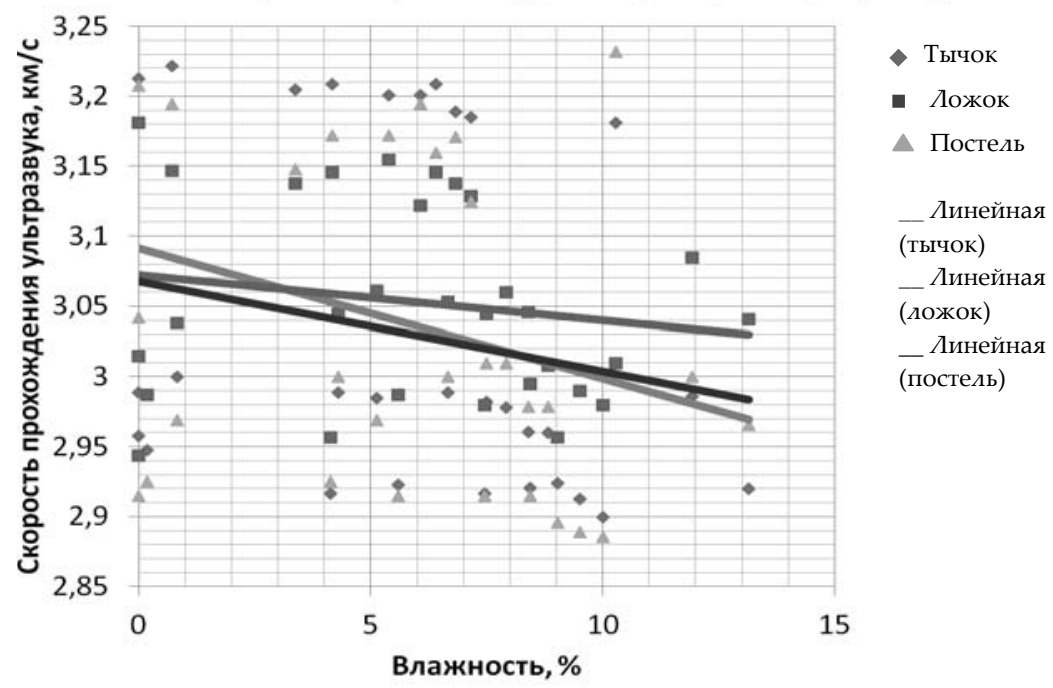

Рис. 7. График зависимости скорости прохождения ультразвука от влажности по трем направлениям кирпича

прочности кирпича в реальных условиях при отрицательной температуре.

Зимнее время для возведения каменных конструкций определяется среднесуточной температурой наружного воздуха $5{ }^{\circ} \mathrm{C}$ и ниже, а также минимальной суточной температурой, равной $0{ }^{\circ} \mathrm{C}$ и ниже.

Прочность кирпичной кладки в основном зависит от прочности кирпича и в значительно меньшей мере от прочности раствора. Именно поэтому потеря 20 \% прочности пластичным цементным раствором в дальнейшем мало отразится на несущей способности кладки. Необходимое же сцепление раствора с кирпичом под тяжестью сжатой кладки будет полностью обеспечено.

В результате нахождения в условиях низкой температуры вода в порах материала кристалдизу- ется, и показания приборов могут оказаться завышенными.

Для определения разницы в показаниях были использованы приборы неразрушающего определения прочности. Процесс выполнения замеров изображен на рис. 8-9.

Результаты замеров скорости ультразвука приборами неразрушающего контроля представлены в табл. 1. Разница скорости ультразвука составдяет от 3 до 10 \% между замороженным и сухим состоянием.

При обследовании и оценке технического состояния каменных конструкций необходимо учитывать особенности их работы и разрушения, обусловленные их структурой.

Каменная кладка является неоднородным упругопластическим телом, состоящим из камней и швов, за-

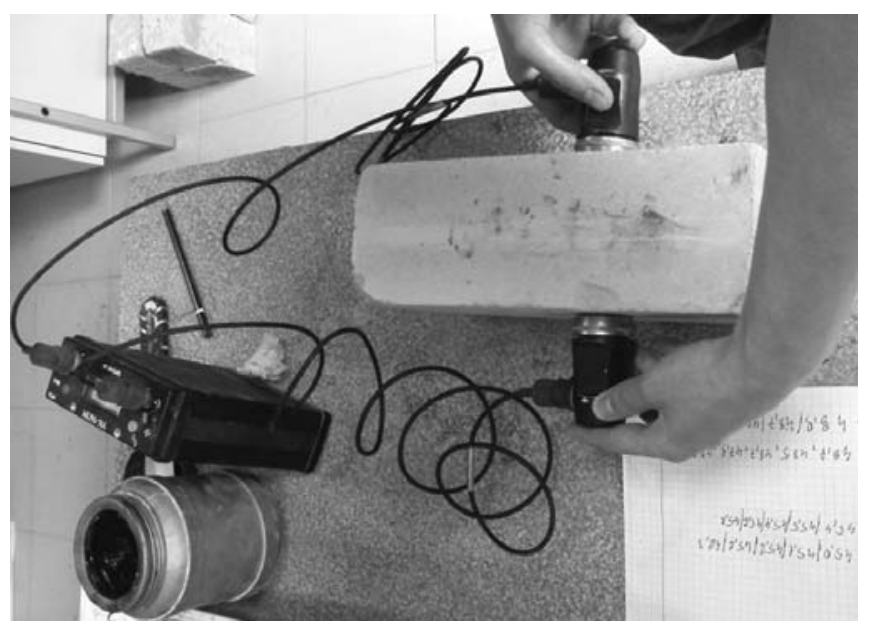

Рис. 8. Определение прочности кирпича с помощью прибора УК 14 ПМ 


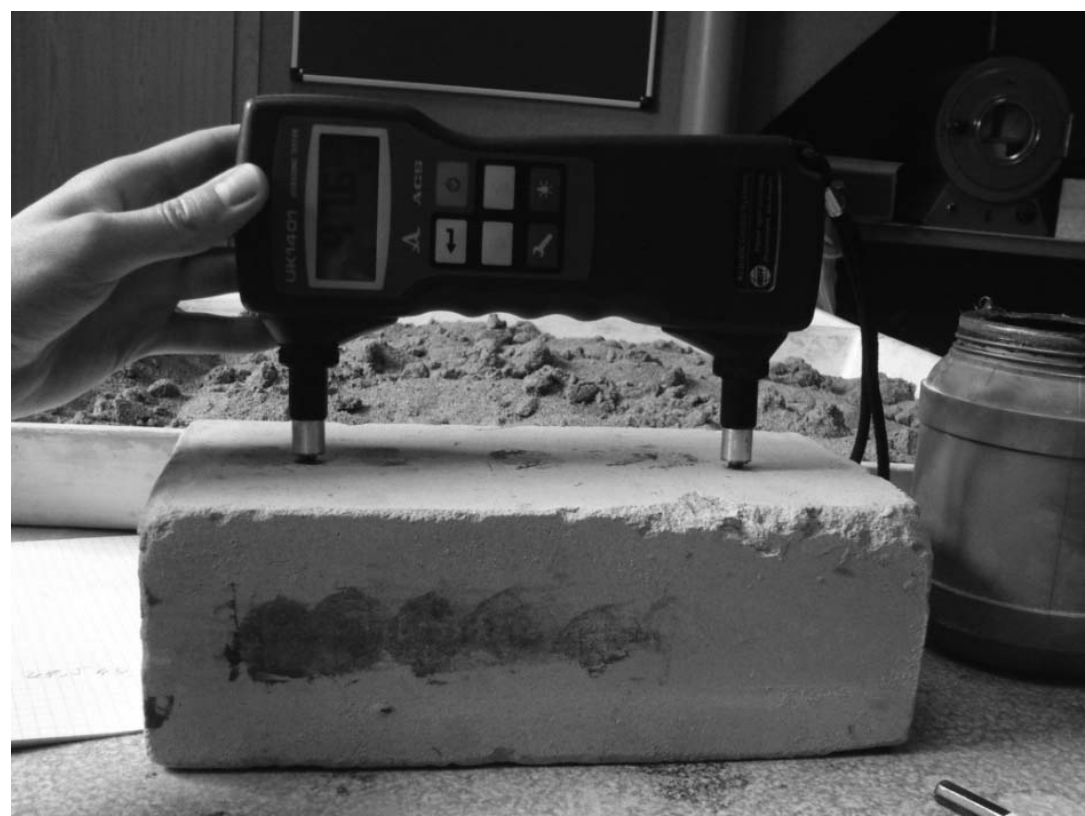

Рис. 9. Определение прочности кирпича с помощью прибора УК 1401

Таблица 1

Скорость распространения ультразвуковых волн для силикатного кирпича

\begin{tabular}{|l|c|c|c|c|}
\hline \multirow{2}{*}{ Состояние образца } & \multicolumn{2}{|c|}{ УК-14ПМ } & \multicolumn{2}{c|}{ УК 1401} \\
\cline { 2 - 5 } & Ложок & Постель & Ложок & Постель \\
\hline \multirow{3}{*}{ Замороженное } & 3,1327 & 3,2051 & 3,3220 & 3,2794 \\
\cline { 2 - 5 } & 3,0863 & 3,0635 & 3,3014 & 3,2938 \\
\hline \multirow{3}{*}{ Сухое } & 2,8863 & 2,9668 & 3,1019 & 3,0700 \\
\cline { 2 - 5 } & 3,0504 & 3,1413 & 3,3527 & 3,3069 \\
\cline { 2 - 5 } & 3,0048 & 3,0643 & 3,3084 & 3,2792 \\
\hline
\end{tabular}

полненных раствором. Этим обусловливаются следующие особенности ее работы: при сжатии кладки усилие передается неравномерно вследствие местных неровностей и неодинаковой плотности отдельных участков затвердевшего раствора. В результате камни подвергаются не только сжатию, но также изгибу и срезу.

Характер разрушения кладки и степень влияния многочисленных факторов на прочность объясняется особенностями ее напряженного состояния при сжатии. Разрушение обычной кирпичной кладки при сжатии начинается с появления отдельных вертикальных трещин, как правило, над и под вертикальными швами, что объясняется явлением изгиба и среза камня, а также концентрацией растягивающих напряжений над этими швами.

В ходе проведения обследования для оценки прочности кирпичной кладки извлекаются образцы из менее нагруженных мест, например, в подоконной зоне. Прочность кирпича и раствора кладки в простенках и в сплошных участках стен в наиболее нагруженных местах обычно оценивается с помощью методов неразрушающего контроля.

Для определения влияния дефектов на показания приборов неразрушающего определения прочности был поставлен эксперимент, который преследовал несколько целей:

1. Оценить возможность применения неразрушающих методов для определения прочности каменной кладки.

2. Сравнить показания прибора сквозного (УК14 ПМ) и поверхностного (УК 1401) прозвучивания.

3. Выявить изменение прочности кладки из сидикатного кирпича в зависимости от возможных повреждений. 
Повреждения и дефекты в кладке встречаются достаточно часто. Наиболее распространенными из них явдяются:

1) некачественная перевязка швов каменной кладки;

2) утолщение горизонтальных швов в каменной кладке;

3) плохое заполнение вертикальных швов в каменной кладке;

4) некачественное армирование каменной кладки;

5) кладка кирпича на обледенелую поверхность;

6) снижение марки кирпича и раствора;

7) "подмолаживание" раствора.

Моделирование кладки предполагало создание нескольких партий образцов с повреждениями и ряд контрольных образцов без них для оценки расхождения результатов.

В данном случае рассматривались пять моделей кладки:

1) без повреждений;

2) без заполнения вертикальных швов;

3) несквозная трещина в среднем ряду кладки;

4) несквозная трещина на три ряда кладки;

5) сквозная трещина на три ряда кладки.

Каждая модель предполагала создание трех образцов для минимизации появления случайного результата. Размеры образцов представлены на рис. 10.

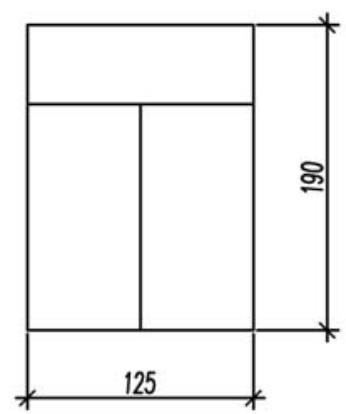

Рис. 10. Размеры кирпичной кладки из моделей кирпича

Третья, четвертая и пятая модели предполагали наличие трещин. Схема образцов изображена на рис. 11-13.
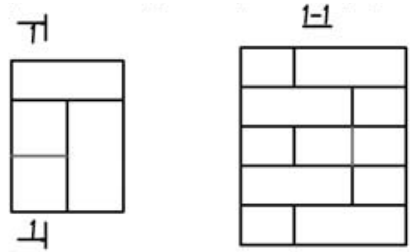

Рис. 11. Несквозная трещина в среднем ряду кладки

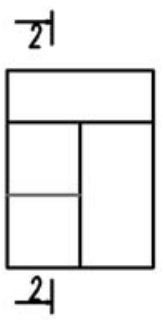

$\underline{2-2}$

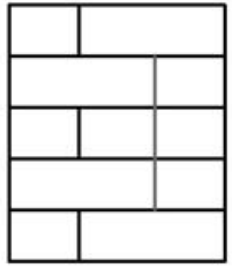

Рис. 12. Несквозная трещина на три ряда кладки

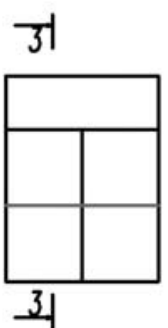

3-3

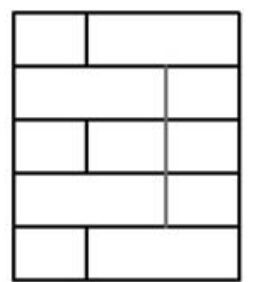

Рис. 13. Сквозная трещина на три ряда кладки

В процессе эксперимента замеры осуществляАись двумя приборами: УК-14 ПМ и УК 14-01. На рис. 14-15 изображены направления прохождения ультразвука для каждого из них.
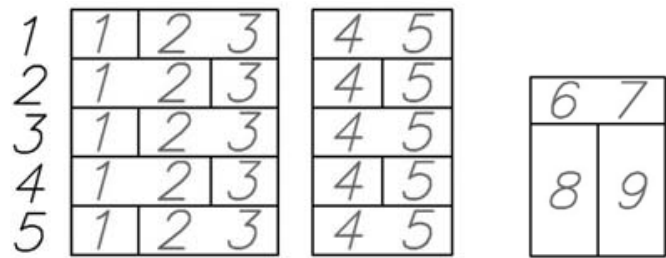

Рис. 14. Точки замера скорости прохождения ультразвука прибором сквозного прозвучивания УК-14 ПМ

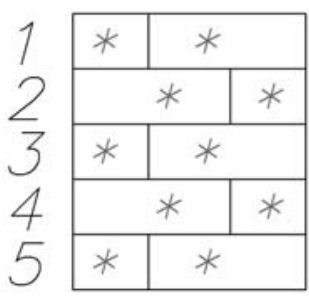

Рис. 15. Точки замера скорости прохождения ультразвука прибором поверхностного прозвучивания УК 1401

Результаты проведения эксперимента представлены в табл. 2.

В ходе замера образца под номером три в пятой модели прибор УК -1401 не показал значения скорости ультразвука из-за повреждения.

Средние значения прохождения скорости ультразвука в кирпичной кладке в разных направлениях представлены в табл. 3. 
Значения скорости ультразвука в кирпичной кладке

\begin{tabular}{|c|c|c|c|c|}
\hline Модель & Номер образца & УК -14 ПМ & УК -1401 & Разница, \% \\
\hline \multirow[t]{3}{*}{1} & 1 & 3,005 & 2,726 & 9,28 \\
\hline & 2 & 3,024 & 2,237 & 26,03 \\
\hline & 3 & 3,031 & 2,355 & 22,31 \\
\hline \multirow[t]{3}{*}{2} & 1 & 2,284 & 1,803 & 39,58 \\
\hline & 2 & 3,051 & 1873 & 38,61 \\
\hline & 3 & 2,873 & 1,880 & 34,56 \\
\hline \multirow[t]{3}{*}{3} & 1 & 2,949 & 2,612 & 11,43 \\
\hline & 2 & 2,983 & 2,203 & 26,15 \\
\hline & 3 & 2,958 & 2,672 & 9,67 \\
\hline \multirow[t]{3}{*}{4} & 1 & 2,902 & 2,066 & 28,81 \\
\hline & 2 & 2,935 & 2,394 & 18,43 \\
\hline & 3 & 2,874 & 2,467 & 14,16 \\
\hline \multirow[t]{3}{*}{5} & 1 & 2,898 & 2,108 & 27,26 \\
\hline & 2 & 2,809 & 1,975 & 29,69 \\
\hline & 3 & 2,524 & - & - \\
\hline
\end{tabular}

Таблица 3

Средние значения прохождения скорости ультразвука в кирпичной кладке

\begin{tabular}{|c|c|}
\hline Направление & Скорость, км/с \\
\hline Тычок & 3,018 \\
\hline Два ложка + шов & 2,898 \\
\hline Два дожка + воздух & 2,908 \\
\hline При наличии дефекта & От 2,62 до 2,985 \\
\hline
\end{tabular}

По результатам эксперимента можно сделать следующие выводы:

1. Методы сквозного и поверхностного прозвучивания при исследовании кладки без повреждений дают сопоставимые результаты. Если же в ней выявлены нарушения, то результаты имеют значительное расхождение.

2. Применение разных методов неразрушающего определения прочности кладки из силикатного кирпича возможно только после создания специальной методики.

\section{БИБЛИОГРАФИЧЕСКИЙ СПИСОК}

1. ГОСТ 379-95. Кирпич и камни силикатные. Технические условия. Госстрой СССР [Текст]. - М., 1995.

2. ГОСТ 24332-88. Кирпич и камни силикатные. Ультразвуковой метод определения прочности при сжатии [Текст] / Госстрой СССР. - М., 1988.

3. Зубанов, С.В. Возможность моделирования кирпичной кладки и оценка ее прочностных характеристик ультразвуковым методом. МСНТ. Итоги диссертационных исследований [Текст] / С.В. Зубанов // Материалы IV Всероссийского конкурса мододых ученых. - М., 2012.

(C) Зубанов С.В., Ткачёв Е.В., 2013 